\title{
RUANG TOPOLOGI LEMBUT KABUR
}

\author{
SRI NOVITA SARI \\ Program Studi Matematika, \\ Fakultas Matematika dan Ilmu Pengetahuan Alam, Universitas Andalas, \\ Kampus UNAND Limau Manis Padang, Indonesia. \\ email : srinovita379@gmail.com
}

\begin{abstract}
Abstrak. Dalam artikel ini didefinisikan ruang topologi lembut kabur yang merupakan generalisasi dari teori ruang topologi atas suatu himpunan lembut kabur. Selain itu juga didefinisikan titik interior lembut kabur, himpunan ketetanggaan lembut kabur, dan himpunan penutup lembut kabur. Dari definisi-definisi tersebut diperoleh beberapa hasil terkait.

Kata Kunci: Ruang Topologi Lembut Kabur, Titik Interior Lembut Kabur, Himpunan Ketetanggaan Lembut Kabur, Himpunan Penutup Lembut Kabur
\end{abstract}

\section{Pendahuluan}

Sebagian besar metode matematika klasik yang ada dirancang untuk menyelesaikan permasalahan di bidang komputer dan pemodelan yang bersifat tepat. Sedangkan terdapat berbagai permasalahan dalam bidang ekonomi, teknik, lingkungan, serta permasalahan dalam kehidupan sosial lainnya yang tidak bisa diselesaikan hanya dengan mengandalkan metode matematika klasik, hal ini dikarenakan berbagai ketidakpastian dan kesamaran yang muncul dari permasalahan tersebut, sehingga dibutuhkan suatu alat matematika yang dapat dihadapkan pada ketidakpastian dan kesamaran ini.

Suatu teori yang dapat digunakan untuk menyelesaikan permasalahan ketidakpastian dan kesamaran ini adalah teori himpunan kabur yang diperkenalkan pertama kali oleh Zadeh [6]. Suatu himpunan kabur digambarkan oleh fungsi keanggotaannya dimana fungsi ini memiliki nilai antara nol dan satu. Molodtsov [3] memperkenalkan teori himpunan lembut sebagai suatu alat matematika yang juga dapat dihadapkan pada masalah ketidakpastian dan kesamaran.

Teori himpunan lembut kabur yang merupakan kombinasi dari himpunan kabur dan himpunan lembut diperkenalkan pertama kali oleh Maji [2]. Banyak peneliti yang berusaha mengembangkan teori ini dan memberikan beberapa teori baru seperti aplikasi himpunan lembut kabur pada teori grup, dasar-dasar himpunan lembut kabur dan sistem ketetanggaan himpunan lembut kabur.

Pada artikel ini, didefinisikan ruang topologi lembut kabur yang merupakan generalisasi dari teori ruang topologi atas suatu himpunan lembut kabur, serta didefinisikan juga titik interior lembut kabur, himpunan ketetanggan lembut kabur, dan himpunan penutup lembut kabur. 


\section{Landasan Teori}

Pada bagian ini diberikan definisi dari himpunan lembut kabur, ruang topologi, himpunan penutup serta titik interior.

Definisi 2.1. [5] Misalkan A adalah sub-himpunan dari $E,\left(f_{A}, E\right)$ didefinisikan sebagai suatu himpunan lembut kabur di $(U, E)$ dengan

$$
\left(f_{A}, E\right)=\left\{\left(e, f_{A}\right): e \in E\right\}
$$

dimana $f_{A}: E \longrightarrow I^{U}$ adalah suatu pemetaan dengan $f_{A}(e)=\mu_{f_{A}}^{e}, \mu_{f_{A}}^{e}=\bar{O}$ jika $e \in E-A$ dan $\mu_{f_{A}}^{e} \neq \bar{O}$ jika $e \in A$ dengan $\bar{O}(u)=0$ untuk setiap $u \in U$.

Definisi 2.2. [4] Misalkan $X$ adalah suatu himpunan tak kosong dan misalkan $\tau \subseteq \wp(X)$ dimana $\wp(X)$ adalah himpunan kuasa (power set) dari $X$. Maka $\tau$ dikatakan suatu topologi di $X$ jika memenuhi kondisi berikut:

(i) $\emptyset, X \in \tau$.

(ii) Gabungan sebarang dari anggota $\tau$ adalah anggota $\tau$.

(iii) Irisan dari setiap dua anggota $\tau$ adalah anggota $\tau$.

Anggota-anggota $\tau$ disebut himpunan terbuka dan misalkan $A$ adalah sebuah subhimpunan dari $X$ maka $A$ disebut himpunan tertutup jika komplemen $A$ adalah himpunan terbuka. Pasangan $(X, \tau)$ disebut ruang topologi.

Definisi 2.3. [4] Misalkan (X, $\tau$ ) adalah suatu ruang topologi dan misalkan $A$ adalah sebuah sub-himpunan dari $X$. Himpunan penutup (closure set) dari $A$ yang dinotasikan oleh $A^{-}$didefinisikan sebagai irisan dari semua subhimpunansubhimpunan tertutup dari $X$ yang memuat $A$.

Definisi 2.4. [4] Misalkan A adalah sebuah sub-himpunan dari suatu ruang topologi $(X, \tau)$. Sebuah titik $x \in A$ disebut suatu titik interior dari A jika terdapat sebuah himpunan terbuka $B$ sedemikian sehingga $x \in B \subseteq A$. Himpunan semua titik-titik interior dari $A$ dinotasikan dengan $A^{\circ}$ dan $A^{o}$ disebut interior dari $A$.

\section{Ruang Topologi lembut Kabur}

Berikut ini diberikan beberapa definisi dan hasil-hasil terkait ruang topologi lembut kabur.

Definisi 3.1. [5] Misalkan $\left(f_{A}, E\right)$ adalah suatu himpunan lembut kabur di $(U, E)$ dan $\tau_{f}$ adalah koleksi dari subhimpunan-subhimpunan dari $\left(f_{A}, E\right)$, maka $\tau_{f}$ dikatakan suatu ruang topologi lembut kabur di $\left(f_{A}, E\right)$ jika memenuhi kondisi berikut:

(1) $(\Phi, E),\left(f_{A}, E\right) \in \tau_{f}$.

(2) Jika $\left(f_{i_{A}}, E\right) \in \tau_{f}, \operatorname{maka} \sqcup_{i}\left(f_{i_{A}}, E\right) \in \tau_{f}$.

(3) Jika $\left(g_{A}, E\right),\left(h_{A}, E\right) \in \tau_{f}$, maka $\left(g_{A}, E\right) \sqcap\left(h_{A}, E\right) \in \tau_{f}$. 
Pasangan tiga terurut $\left(f_{A}, E, \tau_{f}\right)$ disebut suatu ruang topologi lembut kabur atas $\left(f_{A}, E\right)$ dan setiap anggota dari $\left(f_{A}, E, \tau_{f}\right)$ disebut himpunan terbuka lembut kabur.

Definisi 3.2. [5] Misalkan $\left(f_{A}, E, \tau_{f}\right)$ adalah suatu ruang topologi lembut kabur atas $\left(f_{A}, E\right)$. Suatu sub-himpunan dari $\left(f_{A}, E\right)$ disebut himpunan tertutup lembut kabur (fuzzy soft closed set) jika komplemennya adalah anggota dari $\tau_{f}$.

Teorema 3.3. [5] Misalkan $\left(f_{A}, E, \tau_{f}\right)$ adalah suatu ruang topologi lembut kabur atas $\left(f_{A}, E\right)$, maka:

(1) Himpunan-himpunan lembut kabur $(\rho, E)$ dan $\left(f_{A}, E\right)^{c}$ adalah himpunan tertutup lembut kabur.

(2) Irisan dari sebarang himpunan-himpunan tertutup lembut kabur adalah himpunan tertutup lembut kabur.

(3) Gabungan dari setiap dua himpunan tertutup lembut kabur adalah sebuah himpunan tertutup lembut kabur.

Definisi 3.4. [5] Misalkan $\left(f_{A}, E\right)$ adalah sebuah himpunan lembut kabur di $(U, E)$ dan $P_{x}^{\lambda}(x \in U, \lambda \in(0,1])$ didefinisikan sebagai sebuah titik kabur di $I^{U}$. Jika $\lambda \leq$ $\mu_{f_{A}}^{e}(x)$, untuk setiap $e \in A$, maka $P_{x}^{\lambda}$ termuat di $\left(f_{A}, E\right)$ dan dinotasikan dengan $P_{x}^{\lambda} \in^{\sim}\left(f_{A}, E\right)$.

Definisi 3.5. [5] Misalkan $\left(f_{A}, E, \tau_{f}\right)$ adalah suatu ruang topologi lembut kabur atas $\left(f_{A}, E\right),\left(g_{A}, E\right)$ adalah sebuah sub-himpunan dari $\left(f_{A}, E\right)$ dan $P_{x}^{\lambda}$ adalah sebuah titik kabur di $I^{U}$. Himpunan lembut kabur $\left(g_{A}, E\right)$ dikatakan sebuah himpunan ketetanggaan lembut kabur dari $P_{x}^{\lambda}$ jika terdapat sebuah himpunan lembut kabur terbuka $\left(h_{A}, E\right)$ sedemikian sehingga $P_{x}^{\lambda} \in^{\sim}\left(h_{A}, E\right) \sqsubseteq\left(g_{A}, E\right)$.

Teorema 3.6. [5] Misalkan $\left(f_{A}, E, \tau_{f}\right)$ adalah suatu ruang topologi lembut kabur atas $\left(f_{A}, E\right)$, maka:

(1) Setiap $P_{x}^{\lambda} \in^{\sim}\left(f_{A}, E\right)$ memiliki sebuah himpunan ketetanggaan lembut kabur.

(2) Jika $\left(g_{A}, E\right)$ dan $\left(h_{A}, E\right)$ adalah himpunan ketetanggaan lembut kabur dari $P_{x}^{\lambda}$, maka $\left(g_{A}, E\right) \sqcap\left(h_{A}, E\right)$ adalah juga sebuah himpunan ketetanggaan lembut kabur dari $P_{x}^{\lambda}$.

(3) Jika $\left(g_{A}, E\right)$ adalah sebuah himpunan ketetanggaan lembut kabur dari $P_{x}^{\lambda}$ dan $\left(g_{A}, E\right) \sqsubseteq\left(h_{A}, E\right)$, maka $\left(h_{A}, E\right)$ adalah sebuah himpunan ketetanggaan lembut kabur dari $P_{x}^{\lambda}$.

\section{Bukti.}

(1) $\left(f_{A}, E\right)$ adalah sebuah himpunan terbuka lembut kabur dan $P_{x}^{\lambda} \in \sim\left(f_{A}, E\right)$ $\sqsubseteq\left(f_{A}, E\right)$, maka setidaknya $\left(f_{A}, E\right)$ adalah sebuah himpunan ketetanggaan lembut kabur dari $P_{x}^{\lambda}$.

(2) Misalkan $\left(g_{A}, E\right)$ dan $\left(h_{A}, E\right)$ adalah himpunan ketetanggaan lembut kabur dari $P_{x}^{\lambda}$, maka terdapat himpunan terbuka lembut kabur $\left(g_{1_{A}}, E\right)$ dan $\left(h_{1_{A}}, E\right)$ sedemikian sehingga $P_{x}^{\lambda} \in^{\sim}\left(g_{1_{A}}, E\right) \sqsubseteq\left(g_{A}, E\right)$ dan $P_{x}^{\lambda} \in^{\sim}\left(h_{1_{A}}, E\right) \sqsubseteq\left(h_{A}, E\right)$. 
Oleh sebab itu, $P_{x}^{\lambda} \in^{\sim}\left(g_{1_{A}}, E\right) \sqcap\left(h_{1_{A}}, E\right) \sqsubseteq\left(g_{A}, E\right) \sqcap\left(h_{A}, E\right) \operatorname{dimana}\left(g_{1_{A}}, E\right)$ $\sqcap\left(h_{\left.1_{A}, E\right)}\right.$ adalah himpunan terbuka lembut kabur. De-ngan demikian $\left(g_{A}, E\right)$ $\sqcap\left(h_{A}, E\right)$ adalah sebuah himpunan ketetanggaan lembut kabur dari $P_{x}^{\lambda}$.

(3) Misalkan $\left(g_{A}, E\right)$ adalah sebuah himpunan ketetanggaan lembut kabur dari $P_{x}^{\lambda}$ dan $\left(g_{A}, E\right) \sqsubseteq\left(h_{A}, E\right)$, maka terdapat sebuah himpunan terbuka lembut kabur $\left(g_{1_{A}}, E\right)$ sedemikian sehingga $P_{x}^{\lambda} \in^{\sim}\left(g_{1_{A}}, E\right) \sqsubseteq\left(g_{A}, E\right) \sqsubseteq\left(h_{A}, E\right)$. Oleh karena itu, $\left(h_{A}, E\right)$ adalah sebuah himpunan ketetanggaan lembut kabur dari $P_{x}^{\lambda}$.

Definisi 3.7. [5] Misalkan $\left(f_{A}, E, \tau_{f}\right)$ adalah suatu ruang topologi lembut kabur atas $\left(f_{A}, E\right),\left(g_{A}, E\right)$ adalah sebuah sub-himpunan dari $\left(f_{A}, E\right)$ dan $P_{x}^{\lambda} \in^{\sim}\left(f_{A}, E\right)$. Titik kabur $P_{x}^{\lambda}$ dikatakan sebuah titik interior lembut kabur dari $\left(g_{A}, E\right)$ jika terdapat sebuah himpunan terbuka lembut kabur $\left(h_{A}, E\right)$ sedemikian sehingga $P_{x}^{\lambda} \in^{\sim}$ $\left(h_{A}, E\right) \sqsubseteq\left(g_{A}, E\right)$.

Definisi 3.8. [5] Gabungan semua titik-titik interior lembut kabur dari $\left(g_{A}, E\right)$ disebut interior lembut kabur dari $\left(g_{A}, E\right)$ dan dinotasikan sebagai $\left(g_{A}, E\right)^{\circ}$ sebagai berikut.

$$
\left(g_{A}, E\right)^{o}=\left\{\left(P_{x}^{\lambda}, A\right): P_{x}^{\lambda} \text { adalah titik interior lembut kabur dari }\left(g_{A}, E\right)\right\} .
$$

Teorema 3.9. [5] Misalkan $\left(f_{A}, E, \tau_{f}\right)$ adalah suatu ruang topologi lembut kabur atas $\left(f_{A}, E\right)$ dan $\left(g_{A}, E\right)$ adalah sebuah sub-himpunan dari $\left(f_{A}, E\right)$, maka:

(1) Himpunan lembut kabur $\left(g_{A}, E\right)^{\circ}$ adalah gabungan dari semua himpunan terbuka lembut kabur yang termuat di $\left(g_{A}, E\right)$.

(2) $\left(g_{A}, E\right)^{o} \sqsubseteq\left(g_{A}, E\right)$.

(3) Himpunan lembut kabur $\left(g_{A}, E\right)^{\circ}$ adalah sebuah himpunan terbuka lembut kabur.

(4) Himpunan lembut kabur $\left(g_{A}, E\right)^{\circ}$ adalah himpunan terbuka lembut kabur terbesar yang termuat di $\left(g_{A}, E\right)$.

(5) Himpunan lembut kabur $\left(g_{A}, E\right)$ adalah sebuah himpunan terbuka lembut kabur jika dan hanya jika $\left(g_{A}, E\right)=\left(g_{A}, E\right)^{\circ}$.

\section{Bukti.}

(1) Akan ditunjukkan bahwa $\left(g_{A}, E\right)^{o}=\left\{\left(h_{i_{A}}, E\right):\left(h_{i_{A}}, E\right) \sqsubseteq\left(g_{A}, E\right)\right.$ dan $\left(h_{i_{A}}, E\right)$ adalah himpunan terbuka lembut kabur $\}$. Misalkan $P_{x}^{\lambda} \in^{\sim}\left(g_{A}, E\right)^{o}$, maka terdapat sebuah himpunan terbuka lembut kabur $\left(h_{k_{A}}, E\right)$ sedemikian sehingga $P_{x}^{\lambda} \in^{\sim}\left(h_{k_{A}}, E\right) \sqsubseteq\left(g_{A}, E\right)$. Dengan demikian, $P_{x}^{\lambda} \in \sim \sqcup\left(h_{i_{A}}, E\right)$. Sebaliknya, misalkan $P_{x}^{\lambda} \in^{\sim} \sqcup\left\{\left(h_{A}, E\right) \sqsubseteq\left(g_{A}, E\right)\right.$ dan $\left(h_{A}, E\right)$ adalah himpunan terbuka lembut kabur $\}$, maka berdasarkan definisi dari titik interior lembut kabur maka $P_{x}^{\lambda} \in^{\sim}\left(g_{A}, E\right)^{o}$.

(2) Berdasarkan bukti nomor (1) jelas bahwa $\left(g_{A}, E\right)^{o} \sqsubseteq\left(g_{A}, E\right)$.

(3) Karena gabungan dari himpunan terbuka lembut kabur adalah himpunan terbuka lembut kabur dan $\left(g_{A}, E\right)^{\circ}$ adalah gabungan dari himpunan terbuka lembut kabur, maka jelas bahwa $\left(g_{A}, E\right)^{\circ}$ adalah himpunan terbuka lembut kabur. 
(4) Karena $\left(g_{A}, E\right)^{o}$ adalah gabungan dari semua himpunan terbuka lembut kabur yang termuat di $\left(g_{A}, E\right)$, maka jelas bahwa $\left(g_{A}, E\right)^{\circ}$ adalah himpunan terbuka lembut kabur terbesar yang ada di $\left(g_{A}, E\right)$.

(5) Misalkan $\left(g_{A}, E\right)$ adalah himpunan terbuka lembut kabur. Karena $\left(g_{A}, E\right)^{o}$ himpunan terbuka lembut kabur terbesar yang termuat di $\left(g_{A}, E\right)$, maka $\left(g_{A}, E\right)$ $=\left(g_{A}, E\right)^{o}$. Sebaliknya, misalkan bahwa $\left(g_{A}, E\right)=\left(g_{A}, E\right)^{o}$. Karena $\left(g_{A}, E\right)^{o}$ adalah himpunan terbuka lembut kabur, maka $\left(g_{A}, E\right)$ adalah himpunan terbuka lembut kabur.

Teorema 3.10. [5] Misalkan $\left(f_{A}, E, \tau_{f}\right)$ adalah suatu ruang topologi lembut kabur atas $\left(f_{A}, E\right),\left(g_{A}, E\right)$ dan $\left(h_{A}, E\right)$ adalah dua sub-himpunan dari $\left(f_{A}, E\right)$, maka:

(1) $(\Phi, E)^{o}=(\Phi, E),\left(f_{A}, E\right)^{o}=\left(f_{A}, E\right)$.

(2) $\left(\left(g_{A}, E\right)^{o}\right)^{o}=\left(g_{A}, E\right)^{o}$.

(3) Jika $\left(g_{A}, E\right) \sqsubseteq\left(h_{A}, E\right) \operatorname{maka}\left(g_{A}, E\right)^{o} \sqsubseteq\left(h_{A}, E\right)^{o}$.

(4) $\left(g_{A}, E\right)^{o} \sqcap\left(h_{A}, E\right)^{o}=\left[\left(g_{A}, E\right) \sqcap\left(h_{A}, E\right)\right]^{o}$.

(5) $\left(g_{A}, E\right)^{o} \sqcup\left(h_{A}, E\right)^{o} \sqsubseteq\left[\left(g_{A}, E\right) \sqcup\left(h_{A}, E\right)\right]^{o}$.

\section{Bukti.}

(1) Karena $\left(f_{A}, E, \tau_{f}\right)$ adalah suatu ruang topologi lembut kabur dan berdasarkan Definisi $3.1(1)$, maka $(\Phi, E)^{o}$ dan $\left(f_{A}, E\right)^{\circ}$ adalah himpunan terbuka lembut kabur dan berdasarkan Teorema $3.9(5)$, maka jelas bahwa $(\Phi, E)^{\circ}=(\Phi, E)$ $\operatorname{dan}\left(f_{A}, E\right)^{o}=\left(f_{A}, E\right)$.

(2) Misalkan $\left(g_{A}, E\right)^{\circ}=\left(s_{A}, E\right)$. Karena $\left(s_{A}, E\right)$ adalah sebuah himpunan terbuka lembut kabur, maka $\left(s_{A}, E\right)=\left(s_{A}, E\right)^{o}$, sehingga $\left(\left(g_{A}, E\right)^{o}\right)^{o}=\left(s_{A}, E\right)^{o}=$ $\left(s_{A}, E\right)=\left(g_{A}, E\right)^{o}$.

(3) Misalkan $\left(g_{A}, E\right) \sqsubseteq\left(h_{A}, E\right)$. Karena $\left(g_{A}, E\right)^{o} \sqsubseteq\left(g_{A}, E\right)$, maka $\left(g_{A}, E\right)^{o} \sqsubseteq$ $\left(h_{A}, E\right)$ dan $\left(h_{A}, E\right)^{o}$ adalah himpunan terbuka lembut kabur terbesar yang termuat di $\left(h_{A}, E\right)$. Dengan demikian, $\left(g_{A}, E\right)^{o} \sqsubseteq\left(h_{A}, E\right)^{o}$.

(4) Misalkan $\left(g_{A}, E\right)^{o} \sqsubseteq\left(g_{A}, E\right)$ dan $\left(h_{A}, E\right)^{o} \sqsubseteq\left(h_{A}, E\right)$. Dengan demikian $\left(g_{A}, E\right)^{o}$ $\sqcap\left(h_{A}, E\right)^{o} \sqsubseteq\left(g_{A}, E\right) \sqcap\left(h_{A}, E\right)$. Karena himpunan terbuka lembut kabur terbesar yang termuat di $\left(g_{A}, E\right) \sqcap\left(h_{A}, E\right)$ adalah $\left[\left(g_{A}, E\right) \sqcap\left(h_{A}, E\right)\right]^{o}$, maka $\left(g_{A}, E\right)^{o} \sqcap\left(h_{A}, E\right)^{o} \sqsubseteq\left[\left(g_{A}, E\right) \sqcap\left(h_{A}, E\right)\right]^{o}$. Sebaliknya, misalkan $\left[\left(g_{A}, E\right) \sqcap\right.$ $\left.\left(h_{A}, E\right)\right]^{o} \sqsubseteq\left(g_{A}, E\right)^{o}$ dan $\left[\left(g_{A}, E\right) \sqcap\left(h_{A}, E\right)\right]^{o} \sqsubseteq\left(h_{A}, E\right)^{o}$, maka $\left[\left(g_{A}, E\right) \sqcap\right.$ $\left.\left(h_{A}, E\right)\right]^{o} \sqsubseteq\left(g_{A}, E\right)^{o} \sqcap\left(h_{A}, E\right)^{o}$.

(5) Misalkan $\left(g_{A}, E\right)^{o} \sqsubseteq\left(g_{A}, E\right)$ dan $\left(h_{A}, E\right)^{o} \sqsubseteq\left(h_{A}, E\right)$, kemudian $\left(g_{A}, E\right)^{o} \sqcup$ $\left(h_{A}, E\right)^{o} \sqsubseteq\left(g_{A}, E\right) \sqcup\left(h_{A}, E\right)$. Himpunan terbuka lembut kabur terbesar yang termuat di $\left(g_{A}, E\right) \sqcup\left(h_{A}, E\right)$ adalah $\left[\left(g_{A}, E\right) \sqcup\left(h_{A}, E\right)\right]^{o}$, sehingga $\left(g_{A}, E\right)^{o} \sqcup$ $\left(h_{A}, E\right)^{o} \sqsubseteq\left[\left(g_{A}, E\right) \sqcup\left(h_{A}, E\right)\right]^{o}$.

Definisi 3.11. [5] Misalkan $\left(f_{A}, E, \tau_{f}\right)$ adalah suatu ruang topologi lembut kabur atas $\left(f_{A}, E\right),\left(g_{A}, E\right)$ adalah sebuah sub-himpunan dari $\left(f_{A}, E\right)$. Irisan dari semua himpunan tertutup lembut kabur yang memuat $\left(g_{A}, E\right)$ disebut himpunan penutup lembut kabur dari $\left(g_{A}, E\right)$ dan dinotasikan sebagai $\left(g_{A}, E\right)^{-}$.

$$
\left(g_{A}, E\right)^{-}=\sqcap\left(h_{i_{A}}, E\right)
$$


dengan $\left(g_{A}, E\right) \sqsubseteq\left(h_{i_{A}}, E\right)$ dan $\left(h_{i_{A}}, E\right)$ adalah himpunan tertutup lembut kabur.

Teorema 3.12. [5] Misalkan $\left(f_{A}, E, \tau_{f}\right)$ adalah suatu ruang topologi lembut kabur atas $\left(f_{A}, E\right),\left(g_{A}, E\right)$ dan $\left(s_{A}, E\right)$ adalah dua sub-himpunan dari $\left(f_{A}, E\right)$, maka:

(1) Himpunan lembut kabur $\left(g_{A}, E\right)^{-}$adalah sebuah himpunan tertutup lembut kabur.

(2) $\left(g_{A}, E\right) \sqsubseteq\left(g_{A}, E\right)^{-}$.

(3) Himpunan lembut kabur $\left(g_{A}, E\right)^{-}$adalah himpunan tertutup lembut kabur terkecil yang memuat $\left(g_{A}, E\right)$.

(4) Jika $\left(g_{A}, E\right) \sqsubseteq\left(s_{A}, E\right) \operatorname{maka}\left(g_{A}, E\right)^{-} \sqsubseteq\left(s_{A}, E\right)^{-}$.

(5) Himpunan lembut kabur $\left(g_{A}, E\right)$ adalah himpunan tertutup lembut kabur jika dan hanya jika $\left(g_{A}, E\right)=\left(g_{A}, E\right)^{-}$.

(6) $\left(\left(g_{A}, E\right)^{-}\right)^{-}=\left(g_{A}, E\right)^{-}$.

(7) $\left[\left(g_{A}, E\right) \sqcup\left(s_{A}, E\right)\right]^{-}=\left(g_{A}, E\right)^{-} \sqcup\left(s_{A}, E\right)^{-}$.

(8) $\left[\left(g_{A}, E\right) \sqcap\left(s_{A}, E\right)\right]^{-} \sqsubseteq\left(g_{A}, E\right)^{-} \sqcap\left(s_{A}, E\right)^{-}$.

\section{Bukti.}

(1) Karena irisan dari himpunan tertutup lembut kabur adalah himpunan tertutup lembut kabur dan $\left(g_{A}, E\right)^{-}$adalah irisan dari himpunan tertutup lembut kabur, maka jelas bahwa $\left(g_{A}, E\right)^{-}$adalah himpunan tertutup lembut kabur.

(2) Berdasarkan definisi dari penutup lembut kabur jelas bahwa $\left(g_{A}, E\right) \sqsubseteq\left(g_{A}, E\right)^{-}$.

(3) Karena $\left(g_{A}, E\right)^{-}$adalah irisan dari semua himpunan tertutup lembut kabur yang memuat $\left(g_{A}, E\right)$, maka jelas bahwa $\left(g_{A}, E\right)^{-}$adalah himpunan tertutup lembut kabur terkecil yang memuat $\left(g_{A}, E\right)$.

(4) Misalkan $\left(g_{A}, E\right) \sqsubseteq\left(s_{A}, E\right)$. Karena $\left(s_{A}, E\right) \sqsubseteq\left(s_{A}, E\right)^{-}$, maka $\left(g_{A}, E\right) \sqsubseteq$ $\left(s_{A}, E\right)^{-}$. Himpunan tertutup lembut kabur terkecil yang memuat $\left(g_{A}, E\right)$ adalah $\left(g_{A}, E\right)^{-}$, dengan demikian $\left(g_{A}, E\right)^{-} \sqsubseteq\left(s_{A}, E\right)^{-}$.

(5) Misalkan $\left(g_{A}, E\right)$ adalah himpunan tertutup lembut kabur. Karena $\left(g_{A}, E\right)^{-}$ himpunan tertutup lembut kabur terkecil yang memuat $\left(g_{A}, E\right)$, maka $\left(g_{A}, E\right)$ $=\left(g_{A}, E\right)^{-}$. Sebaliknya, misalkan bahwa $\left(g_{A}, E\right)=\left(g_{A}, E\right)^{-}$. Karena $\left(g_{A}, E\right)^{-}$ adalah himpunan tertutup lembut kabur, maka $\left(g_{A}, E\right)$ adalah himpunan tertutup lembut kabur.

(6) Misalkan $\left(g_{A}, E\right)^{-}$adalah himpunan tertutup lembut kabur dan $\left(g_{A}, E\right)^{-}=$ $\left(k_{A}, E\right)$, maka $\left(k_{A}, E\right)$ adalah himpunan tertutup lembut kabur. Berdasarkan Teorema 3.12(5), maka $\left(k_{A}, E\right)=\left(k_{A}, E\right)^{-}$. Dengan demikian, $\left(\left(g_{A}, E\right)^{-}\right)^{-}=$ $\left(k_{A}, E\right)^{-}=\left(k_{A}, E\right)=\left(g_{A}, E\right)^{-}$

(7) Misalkan $\left(g_{A}, E\right) \sqsubseteq\left(g_{A}, E\right) \sqcup\left(s_{A}, E\right) \operatorname{dan}\left(s_{A}, E\right) \sqsubseteq\left(g_{A}, E\right) \sqcup\left(s_{A}, E\right)$. Berdasarkan Teorema 3.12(4), maka $\left(g_{A}, E\right)^{-} \sqsubseteq\left[\left(g_{A}, E\right) \sqcup\left(s_{A}, E\right)\right]^{-}$dan $\left(s_{A}, E\right)^{-} \sqsubseteq\left[\left(g_{A}, E\right) \sqcup\left(s_{A}, E\right)\right]^{-}$. Dengan demikian, $\left(g_{A}, E\right)^{-} \sqcup\left(s_{A}, E\right)^{-} \sqsubseteq$ $\left[\left(g_{A}, E\right) \sqcup\left(s_{A}, E\right)\right]^{-}$. Misalkan $\left(g_{A}, E\right) \sqcup\left(s_{A}, E\right) \sqsubseteq\left(g_{A}, E\right)^{-} \sqcup\left(s_{A}, E\right)^{-}$dan $\left(g_{A}, E\right)^{-} \sqcup\left(s_{A}, E\right)^{-}$adalah sebuah himpunan tertutup lembut kabur. Karena $\left[\left(g_{A}, E\right) \sqcup\left(s_{A}, E\right)\right]^{-}$adalah sebuah himpunan tertutup lembut kabur terkecil yang memuat $\left(g_{A}, E\right) \sqcup\left(s_{A}, E\right)$, maka $\left[\left(g_{A}, E\right) \sqcup\left(s_{A}, E\right)\right]^{-} \sqsubseteq\left(g_{A}, E\right)^{-} \sqcup$ $\left(s_{A}, E\right)^{-}$. Dengan demikian, $\left[\left(g_{A}, E\right) \sqcup\left(s_{A}, E\right)\right]^{-}=\left(g_{A}, E\right)^{-} \sqcup\left(s_{A}, E\right)^{-}$. 
(8) Karena $\left(g_{A}, E\right) \sqsubseteq\left(g_{A}, E\right)^{-} \operatorname{dan}\left(s_{A}, E\right) \sqsubseteq\left(s_{A}, E\right)^{-}$, maka $\left(g_{A}, E\right) \sqcap\left(s_{A}, E\right)$ $\sqsubseteq\left(g_{A}, E\right)^{-} \sqcap\left(s_{A}, E\right)^{-}$dan $\left(g_{A}, E\right)^{-} \sqcap\left(s_{A}, E\right)^{-}$adalah himpunan tertutup lembut kabur. Himpunan tertutup lembut kabur terkecil yang memuat $\left(g_{A}, E\right)$ $\sqcap\left(s_{A}, E\right)$ adalah $\left[\left(g_{A}, E\right) \sqcap\left(s_{A}, E\right)\right]^{-}$, sehingga $\left[\left(g_{A}, E\right) \sqcap\left(s_{A}, E\right)\right]^{-} \sqsubseteq\left(g_{A}, E\right)^{-}$ $\sqcap\left(s_{A}, E\right)^{-}$.

\section{Kesimpulan}

Generalisasi teori ruang topologi atas suatu himpunan lembut kabur memperlihatkan bahwa definisi, teorema, lema, dan proposisi serta sifat-sifat yang berlaku di ruang topologi biasa juga berlaku di ruang topologi lembut kabur.

\section{Daftar Pustaka}

[1] Kannan, K. 2005. Soft Generalized Closed Sets in Soft Topological Spaces. Journal of Theoretical and Applied Informatio Technology 37 (1) : $17-21$

[2] Maji, P. K. R. Biswas and A. R. Roy. 2003. Soft Set Theory. Comput. Math. Appl. 45 : $555-562$

[3] Molodtsov, D. 1999. Soft Set Theory-First Results. Comput. Math. Appl. 37 : $19-31$

[4] Mordeson, John N and Premchand S. Nair. 2001. Fuzzy Mathematics. SpringerVerlag. Germany

[5] Simsekler, Tugbahan and Saziye Yuksel. 2013. Fuzzy soft topological spaces. Annals of Fuzzy Mathematics and Informatics 5 : $87-96$

[6] Zadeh, L.A. 1965. Fuzzy Sets. Inform. Control. $8: 338-353$ 